\title{
Resistance to hypoxia-induced necroptosis is conferred by glycolytic pyruvate scavenging of mitochondrial superoxide in colorectal cancer cells
}

\author{
C-Y Huang ${ }^{1}$, W-T Kuo ${ }^{1}$, Y-C Huang ${ }^{1}$, T-C Lee ${ }^{1,2}$ and LCH Yu ${ }^{*, 1}$
}

Cancer cells may survive under oxygen and nutrient deprivation by metabolic reprogramming for high levels of anaerobic glycolysis, which contributes to tumor growth and drug resistance. Abnormally expressed glucose transporters (GLUTs) are colocalized with hypoxia $(\mathrm{Hx})$ inducible factor $(\mathrm{HIF}) 1 \alpha$ in peri-necrotic regions in human colorectal carcinoma. However, the underlying mechanisms of anti-necrotic resistance conferred by glucose metabolism in hypoxic cancer cells remain poorly understood. Our aim was to investigate signaling pathways of $\mathrm{Hx}$-induced necroptosis and explore the role of glucose pyruvate metabolite in mechanisms of death resistance. Human colorectal carcinoma cells were $\mathrm{Hx}$ exposed with or without glucose, and cell necroptosis was examined by receptor-interacting protein (RIP) $1 / 3$ kinase immunoprecipitation and ${ }^{32} \mathrm{P}$ kinase assays. Our results showed increased RIP1/3 complex formation and phosphorylation in hypoxic, but not normoxic cells in glucose-free media. Blocking RIP1 signaling, by necrostatin-1 or gene silencing, decreased lactodehydrogenase (LDH) leakage and plasma membrane disintegration. Generation of mitochondrial superoxide was noted after hypoxic challenge; its reduction by antioxidants inhibited RIP signaling and cell necrosis. Supplementation of glucose diminished the RIP-dependent LDH leakage and morphological damage in hypoxic cells, whereas non-metabolizable sugar analogs did not. Hypoxic cells given glucose showed nuclear translocation of HIF1 $\alpha$ associated with upregulation of GLUT-1 and GLUT-4 expression, as well as increase of intracellular ATP, pyruvate and lactate levels. The glucose-mediated death resistance was ablated by iodoacetate (an inhibitor to glyceraldehyde-3-phosphate dehydrogenase), but not by UK5099 (an inhibitor to mitochondrial pyruvate carrier), suggesting that glycolytic pathway was involved in anti-necrotic mechanism. Lastly, replacing glucose with cell-permeable pyruvate derivative also led to decrease of $\mathrm{Hx}$-induced necroptosis by suppression of mitochondrial superoxide in an energy-independent manner. In conclusion, glycolytic metabolism confers resistance to RIP-dependent necroptosis in hypoxic cancer cells partly through pyruvate scavenging of mitochondrial free radicals.

Cell Death and Disease (2013) 4, e622; doi:10.1038/cddis.2013.149; published online 2 May 2013

Subject Category: Cancer Metabolism

Malignant cells have developed adaptive mechanisms to survive under extreme conditions of tumor microenvironment, such as restricted oxygen supply and nutrients deprivation. The altered bioenergetic status may contribute to tumor growth and drug resistance against antiangiogenic and chemotherapeutic agents. ${ }^{1,2}$ One of the pro-survival mechanism of tumor cells is the high levels of anaerobic glycolysis, termed Warburg's effect. ${ }^{3}$ A large body of evidence shows that upregulation of glycolytic enzymes and glucose transporters (GLUTs) are linked to transcription activity of hypoxia (Hx) inducible factor (HIF) 1 triggered by low oxygen condition. ${ }^{4,5}$ Moreover, presence of GLUT isoforms 1-4 and sodium/glucose transporter 1 (SGLT1), which are not normally expressed in colonocytes, has been widely documented in human colorectal carcinoma that colocalizes with
HIF $1 \alpha^{6-12}$ To date, glucose-mediated mechanisms involved in promoting tumor survival against hypoxic stress remain incompletely understood.

Cells depleted of oxygen and nutrients undergo necrotic death, which is commonly seen in hypoxic cores of colorectal tumors, ${ }^{13,14}$ and also in cases of mesenteric ischemia/ reperfusion and necrotizing enterocolitis. ${ }^{15,16}$ Although necrosis has been traditionally regarded as an uncontrolled form of cell death, recent data indicated that programmed necrosis or necroptosis is regulated by receptor-interacting protein (RIP) kinase through RIP1 and RIP3 complex formation and phosphorylation. ${ }^{17-21}$ Mitochondrial bioenergetic alterations and reactive oxygen species (ROS) derived from respiratory chain have also been implicated as necrotic effectors. ${ }^{18,21}$ However, the molecular mechanisms of $\mathrm{Hx}$-induced necrotic

\footnotetext{
${ }^{1}$ Graduate Institute of Physiology, National Taiwan University College of Medicine, Taipei, Taiwan and ${ }^{2}$ Department of Internal Medicine, National Taiwan University Hospital, Taipei, Taiwan

*Corresponding author: LCH Yu, Graduate Institute of Physiology, National Taiwan University College of Medicine, Suite 1020, \#1 Jen-Ai Rd. Sec. I, Taipei 100, Taiwan. Tel: +886 2 23123456, ext. 88237; Fax: +886 2 23964350; E-mail: Ichyu@ntu.edu.tw

Keywords: receptor-interacting protein kinase; necrotic death; mitochondrial dysfunction; hypoxic stress; glucose metabolism

Abbreviations: RIP, receptor-interacting protein kinase; GPD, glyceraldehyde-3-phosphate dehydrogenase; MPC, mitochondrial pyruvate carrier; LDH, lactodehydrogenase; TER, transepithelial electrical resistance; ROS, reactive oxygen species; GLUT, glucose transporter; SGLT1, sodium/glucose transporter 1; BHA, butylated hydroxyanisole; ZO, zonula occluden; IA, iodoacetate

Received 02.1.13; revised 07.3.13; accepted 03.4.13; Edited by G Melino
} 
death and signaling pathways of anti-necrotic resistance in cancer cells are still unclear.

Recent reports documented that HIF1 $\alpha$ and GLUT-1 colocalize at peri-necrotic regions in human colorectal tumors, ${ }^{13,22}$ suggesting that glucose metabolism may confer anti-necrotic resistance to hypoxic stress. Glucose is catalyzed to ATP and pyruvate by a cascade of glycolytic enzymes, such as glucokinase and glyceraldehyde-3-phosphate dehydrogenase (GPD). ${ }^{23}$ The final glycolytic product pyruvate is also the starting substrate for tricarboxylic acid cycle after being transported across inner mitochondrial membrane by mitochondrial pyruvate carrier (MPC). ${ }^{24,25}$ Aside from its critical role as the link between glycolysis and mitochondrial respiration, pyruvate also scavenges ROS through a non-enzymatic reaction. ${ }^{26}$ Numerous studies have suggested that chemoresistance may be due in part to glycolytic ATP as a preferential energy source for promoting cancer cell survival. ${ }^{27,28}$ However, whether glycolytic pyruvate metabolite has a role in circumventing $\mathrm{Hx}$-induced necrotic death has yet to be explored.

\section{Results}

Hypoxic challenge triggers RIP-dependent necroptosis in human colorectal carcinoma cells. Human colorectal carcinoma Caco-2 cells were exposed to normoxia $(\mathrm{Nx})$ or $\mathrm{Hx}$ in glucose-free media $(\Phi)$ for various time points, and a time-dependent increase of lactodehydrogenase (LDH) leakage was observed in $\mathrm{Hx}+\Phi$ but not $\mathrm{Nx}+\Phi$ cells (Figure 1a). Live images revealed cytosolic vacuolation, widening intercellular space and cell detachment in a timely order following hypoxic challenge, whereas no morphological change was observed in normoxic counterparts (Figure 1b). No sign of apoptosis was found after hypoxic challenge as evidenced by the lack of oligonucleosome formation and caspase-3 activation (Supplementary Figure S1). Similar results of $\mathrm{Hx}$-induced cell necrosis were seen in another human colorectal tumor cell line HT29 (Supplementary Figures S2-A and B).

The mitochondrial transmembrane potential was determined by using a cationic JC-1 dye. Exposure to Hx resulted in a transient increase and then decline in red fluorescence intensity (the aggregated form of JC-1) followed by a display of green fluorescence (the monomer form of $\mathrm{JC}$-1) in the cytoplasm at later time points (Figure 1c). Quantification results indicated that the ratios of J-aggregate/monomer in cells after 8- and 24-h $\mathrm{Hx}$ were $221.1 \pm 49.0 \%$ and
$20.5 \pm 2.8 \%$, respectively, of that of the normoxic controls (Figure 1d), suggesting that $\mathrm{Hx}$ caused a transient hyperpolarization and a final collapse of mitochondrial transmembrane potential. Furthermore, plasma membrane disintegration paralleled with loss of tight junctions in hypoxic cells, evidenced by reduction of transepithelial electrical resistance (TER), increase of apical-to-basolateral dextran flux and structural disruption of zonula occluden-1 (ZO-1) (Figure 1e-g).

Pretreatment with necrostatin-1 (Nec-1; a specific RIP1 inhibitor) and gene silencing of RIP1 reduced the level of LDH leakage caused by hypoxic challenge (Figures $2 a$ and b). A $\sim 50 \%$ knockdown of RIP1 protein by siRNA was confirmed by western blots (Figure 2b). Using immunoprecipitation and ${ }^{32} \mathrm{P}$ kinase assays, formation of RIP1/3 complex and phosphorylation of RIP1 were found in $\mathrm{Hx}+\Phi$ but not $\mathrm{Nx}+\Phi$ cells (Figure $3 \mathrm{a}$ ), indicating the activation of RIP1/3 signaling. The $\mathrm{Hx}$-induced morphological damage and cell detachment were also inhibited by Nec-1 (Figure 2c). However, the mitochondrial transmembrane potential change was not reverted by Nec-1 (Figure 2d), suggesting that RIP1 activation may not be upstream of mitochondrial dysfunction. In hypoxic cells treated with necrostain-1, a transient increase in red fluorescence was seen after $8 \mathrm{~h}$ followed by a switch to green fluorescence after $24 \mathrm{~h}$ (Figure $2 \mathrm{~d}$ ), of which the quantification results of JC-1 staining were $277.2 \pm 25.2 \%$ and $40.2 \pm 13.6 \%$, compared with normoxic controls with necrostain-1 at respective time points.

Glucose uptake abolishes $\mathrm{Hx}$-induced RIP signaling and necroptosis. Administration of glucose $(25 \mathrm{mM})$ reduced the RIP1/3 complex formation and phosphorylation (Figure 3a) and decreased LDH leakage in hypoxic cells in a dose-dependent manner (Figure 3b). Non-metabolizable sugar analogs (i.e., 3-O-methyl-glucopyranoside and mannitol) or glutamate did not reduce the LDH activity (Supplementary Figure S3). Moreover, glucose addition also ablated $\mathrm{Hx}$-induced morphological damages (data not shown), mitochondrial transmembrane potential damage (Figure 3c) and tight junctional disruption (Figure $3 d-f$ ). Addition of glucose did not modify the apoptotic levels in hypoxic cells (data not shown).

To confirm that cells still perceive hypoxic stress after glucose addition, activation of $\mathrm{HIF} 1 \alpha$ and $\mathrm{Hx}$-targeted genes were examined. Nuclear translocation of HIF1 $\alpha$ (Figure 4a) correlated with increased expression of GLUT-1 and GLUT-4

\footnotetext{
Figure 1 Necrotic death was triggered by hypoxic challenge in human colonic carcinoma cells. (a) Caco-2 cells were exposed to normoxia (Nx) or hypoxia (Hx) in glucosefree media $(\Phi)$ for various time points. Increased LDH activity was found in the cell media of $\mathrm{Hx}+\Phi$, but not $\mathrm{Nx}+\Phi$ cells, in a time-dependent manner. ${ }^{*} P<0.05$ versus $\mathrm{Nx}+\Phi(n=6 /$ group). (b) Representative time-lapse images showing morphological changes in $\mathrm{Hx}+\Phi$ cells for $24 \mathrm{~h}$. Cytosolic vacuolation $(\rightarrow)$ and cell detachment $(\#)$ were noted in $\mathrm{Hx}+\Phi$ cells. (c) Representative time-lapse images showing temporal alterations of mitochondrial transmembrane potential in $\mathrm{Hx}+\Phi$, but not $\mathrm{Nx}+\Phi$ cells. The aggregated form of JC-1 (J-aggregate; red fluorescence) accumulated in functional mitochondria in normoxic cells throughout each time point. In hypoxic cells, a transient increase in red fluorescence intensity was seen after $4-8 \mathrm{~h}$ followed by a decline at later time points (16-24 h) associated with an increase in green fluorescence (the monomer form of JC-1; J-monomer) in the cytoplasm. (d) The ratio of $\mathrm{J}$-aggregate to monomer was quantified in $\mathrm{Nx}+\Phi$ and $\mathrm{Hx}+\Phi$ cells at various time points. In contrast to normoxic cells, hypoxic challenge induces transient hyperpolarization and a final collapse of the mitochondrial transmembrane potential. ${ }^{*} P<0.05$ versus $\mathrm{Nx}+\Phi$ at individual time points ( $n=8$ /group). (e) Hypoxic challenge decreased the transepithelial resistance (TER) of cells compared with normoxic conditions. Data are presented as the absolute TER value at various time points. ${ }^{*} P<0.05$ versus $\mathrm{Nx}+\Phi(n=6 /$ group). (f) Hypoxic cells displayed heightened apical-to-basolateral flux of dextran probe in a timedependent manner. ${ }^{*} P<0.05$ versus $\mathrm{Nx}+\Phi(n=6 /$ group). (g) Representative images of tight junction ZO-1 staining in cells exposed to $\mathrm{Nx}$ and $\mathrm{Hx}$ for $16 \mathrm{~h}$. Tight junction disruption and cell detachment (asterisks) were observed in hypoxic cells ( $n=6 /$ group)
} 


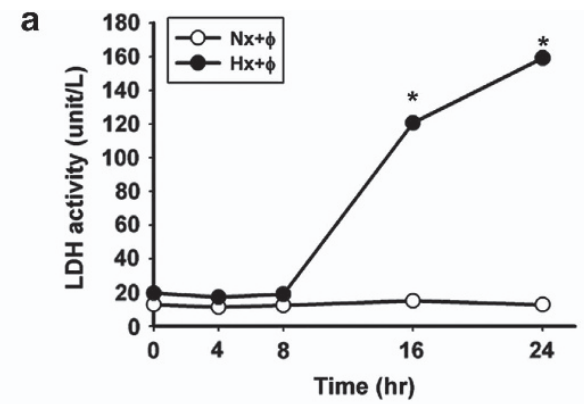

b
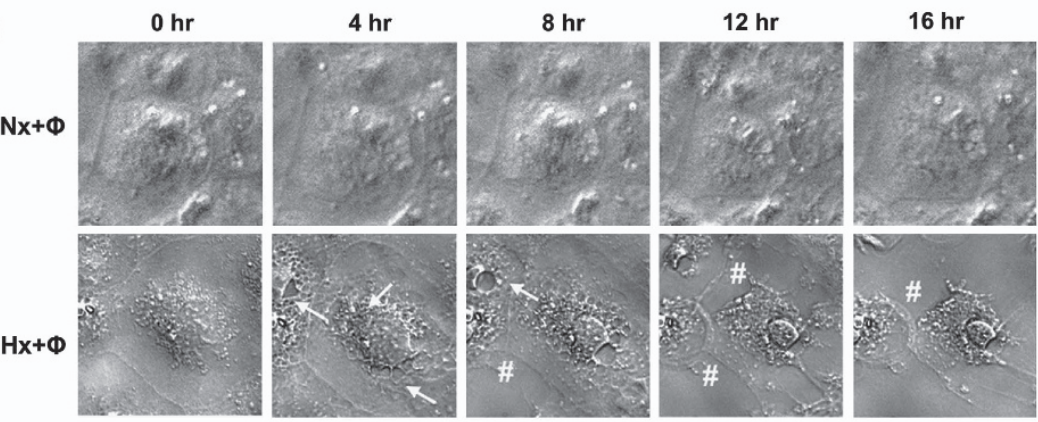

$24 \mathrm{hr}$

C
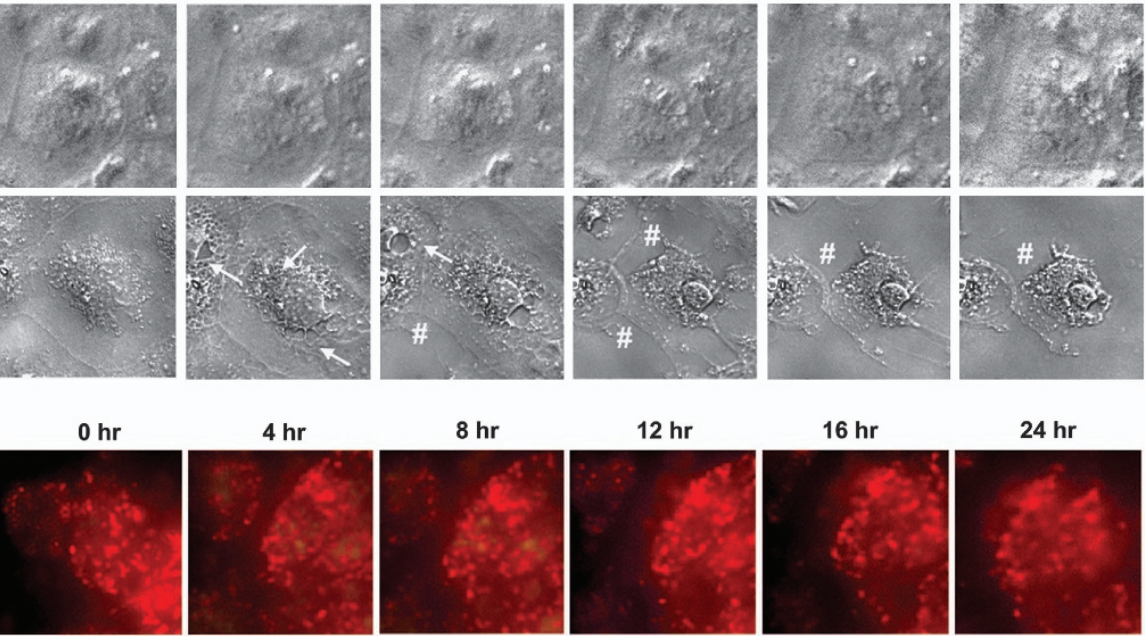

$x+\Phi$
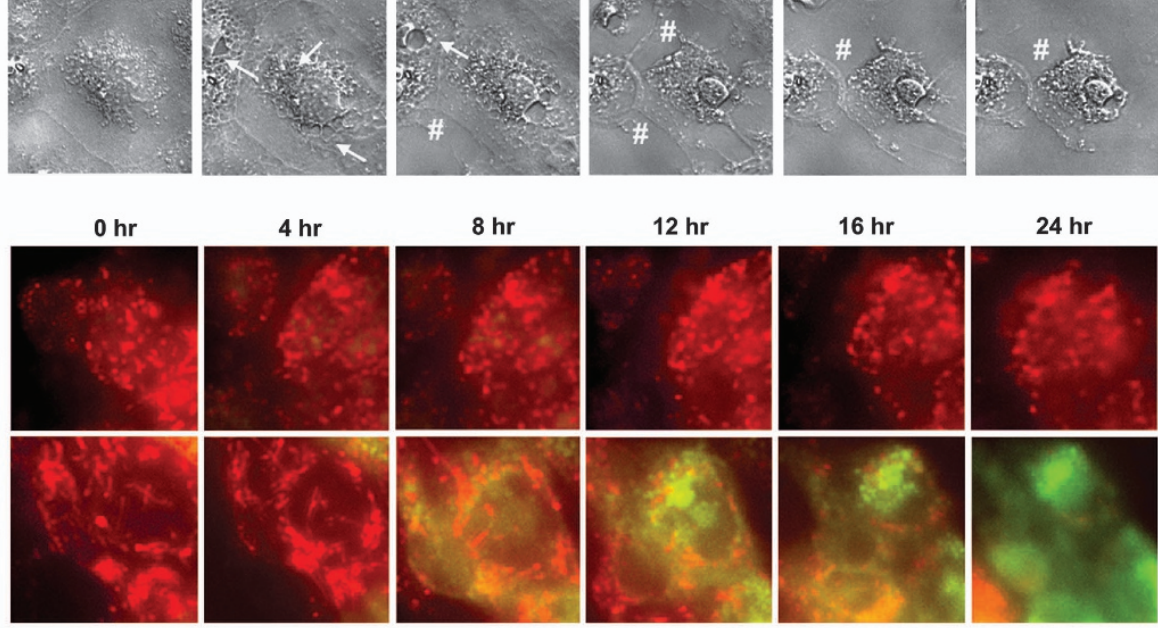

d
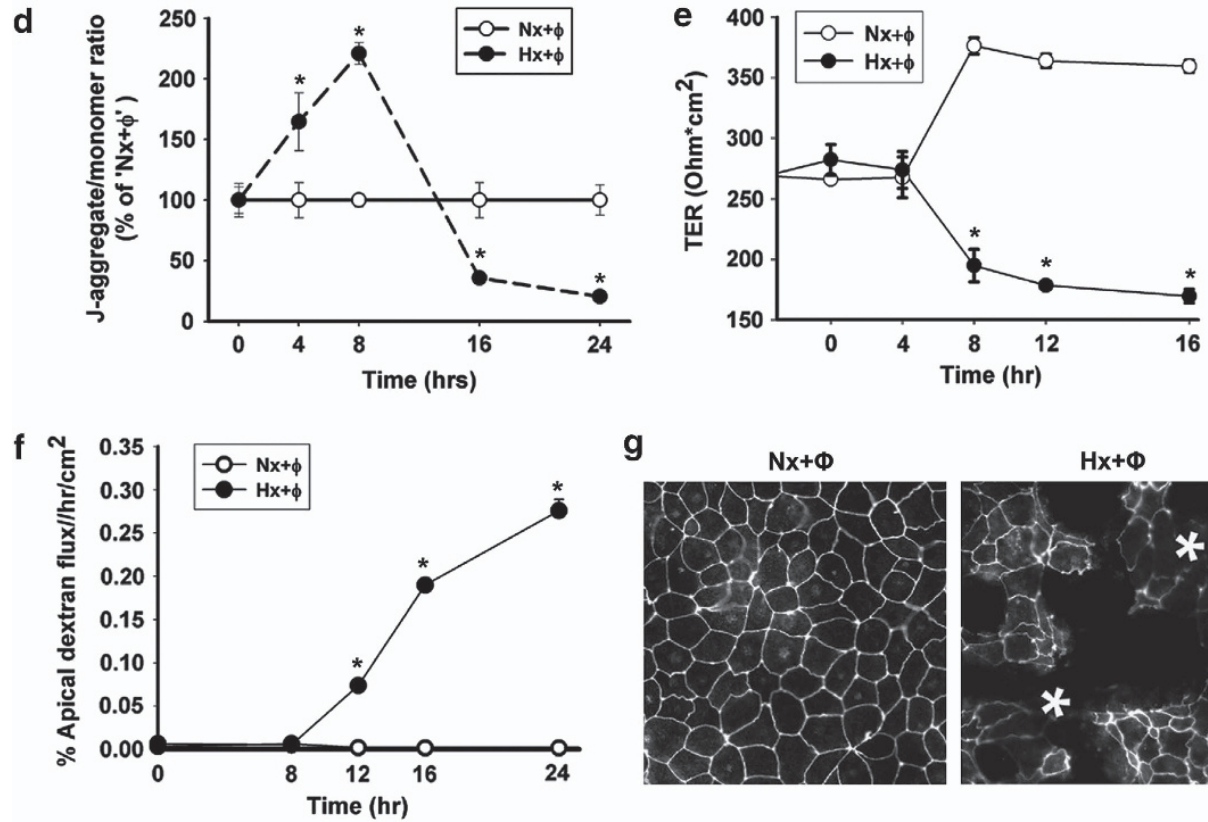

g

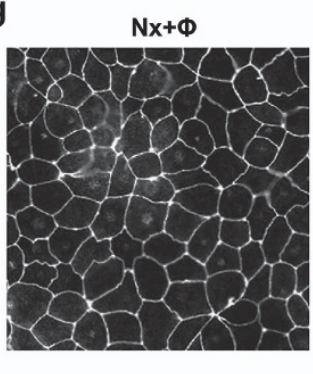

$\mathrm{Hx}+\Phi$

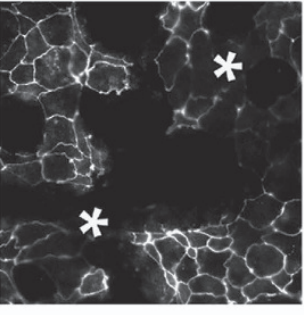



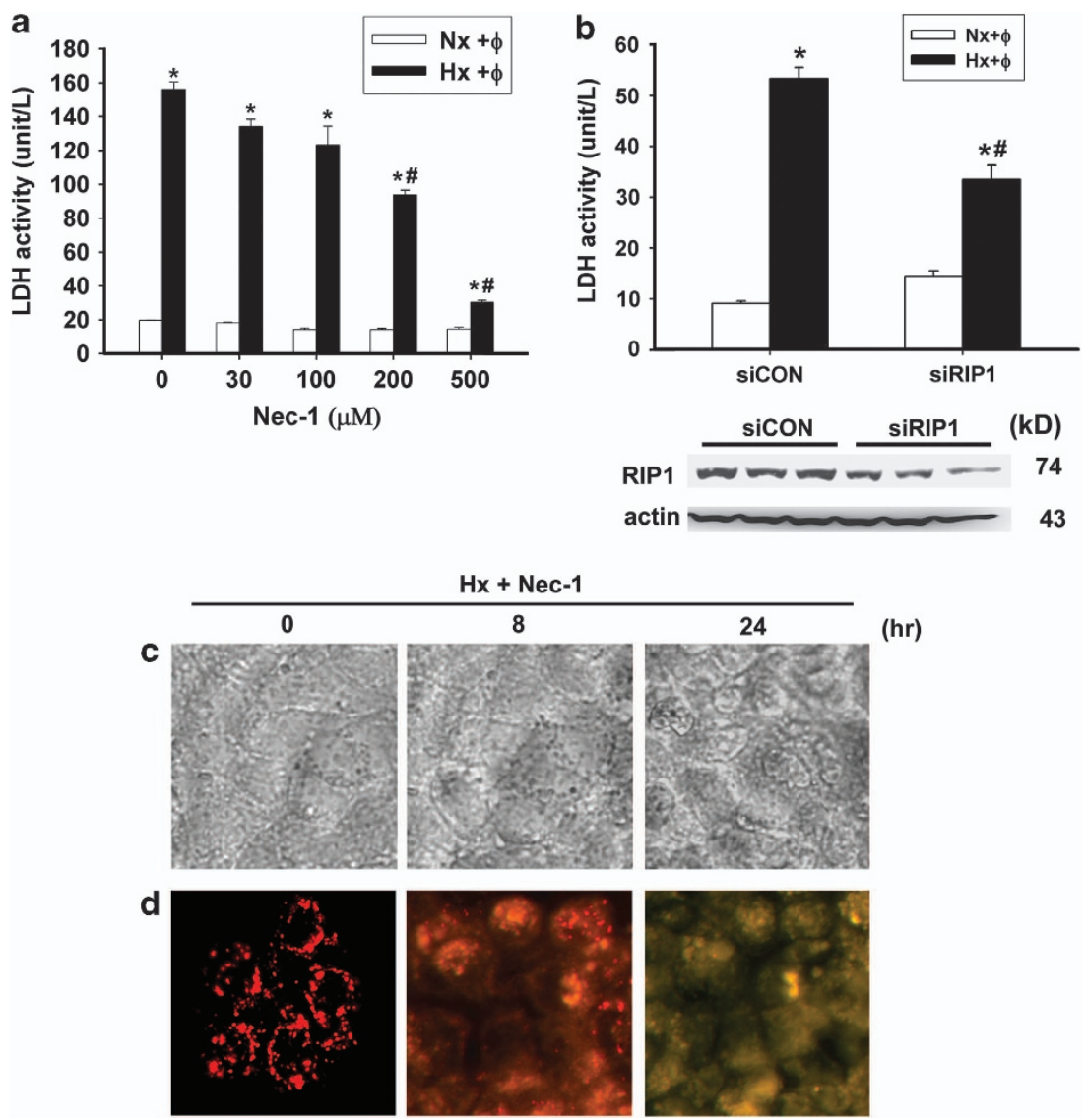

Figure 2 Hypoxia (Hx)-induced necrotic cell death is dependent on RIP signaling pathways. (a) Pretreatment with necrostatin-1 (Nec-1; a specific RIP1 inhibitor) decreased the Hx-induced LDH leakage in a dose-dependent manner. ${ }^{*} P<0.05$ versus respective normoxia $(\mathrm{Nx})+\Phi$ groups; ${ }^{\#} P<0.05$ versus ${ }^{\prime} 0 \mathrm{mM}$ ' in $\mathrm{Hx}+\Phi$ cells $(n=$ 6/group). (b) Knockdown of RIP1 by siRNA reduced LDH leakage in hypoxic cells. No effect was seen by negative control (CON) siRNA. Knockdown efficiency of transfected cells was confirmed by Western blots. ${ }^{*} P<0.05$ versus respective $\mathrm{Nx}+\Phi$ groups. ${ }^{\#} P<0.05$ versus $\operatorname{CON}(n=3 /$ group). (c) Representative images showing that Nec- 1 inhibited morphological damage and cell detachment caused by 8-h and 24-h Hx. (d) Representative images showing transient mitochondrial hyperpolarization (an increase in red fluorescence intensity after $8 \mathrm{~h}$ ) and a final collapse of transmembrane potential (an increase in green fluorescence intensity after $24 \mathrm{~h}$ ) in hypoxic cells treated with Nec-1. The results suggest that RIP1 may not be upstream of mitochondrial dysfunctions ( $n=4 /$ group)

at the transcriptional and translational levels in hypoxic cells given glucose (Figure $4 b-d)$. The experiment was not carried out on hypoxic cells in glucose-free media due to cell necrosis (i.e., plasma membrane disintegration and release of cellular contents). Moreover, similar results of glucose-mediated death resistance, $\mathrm{HIF} 1 \alpha$ activation and GLUT upregulation were also seen in HT29 cells under hypoxic stress (Supplementary Figure S4-A, C, D).

Anaerobic glycolytic metabolism is involved in anti-necrotic resistance to $\mathbf{H x}$ stress. To verify the metabolic process that is involved in death resistance, cells were pretreated with iodoacetate (IA, a glycolytic inhibitor to GPD) and UK5099 (UK, a MPC inhibitor) prior to hypoxic challenge in the presence of glucose. Blockade of glucosemediated resistance was noted in cells pretreated with IA, whereas no inhibitory effect was seen with UK (Figure 5a), suggesting that glycolytic products unrelated to tricarboxylic acid cycles were involved in anti-necrotic mechanisms. For hypoxic cells in glucose-free media, IA and UK had no effect on LDH activity (data not shown).
The intracellular ATP, pyruvate, lactate contents were next quantified to examine the bioenergetic status of cells. A significant reduction of intracellular ATP and pyruvate levels were seen in hypoxic cells compared with their normoxic controls in glucose-free media (Figures $5 b$ and c), whereas comparable lactate production was noted between the two groups (Figure $5 d$ ). Addition of glucose partially prevented the drop of ATP and pyruvate caused by $\mathrm{Hx}$, and significantly increased the lactate contents (Figure $5 b-d$ ). The effect of IA was confirmed by lower levels of ATP, pyruvate and lactate production compared with those given glucose without inhibitors in both normoxic and hypoxic conditions (Figure 5b-d). In contrast, UK had no effect on these parameters (Figure 5b-d).

Pyruvate is involved in death resistance through mitochondrial superoxide scavenging without restoration of cellular energy. The specific role of pyruvate in the mechanisms of death resistance was examined by replacing glucose with cell-permeable ethyl pyruvate derivative in hypoxic cells. Addition of pyruvate derivative significantly 
a

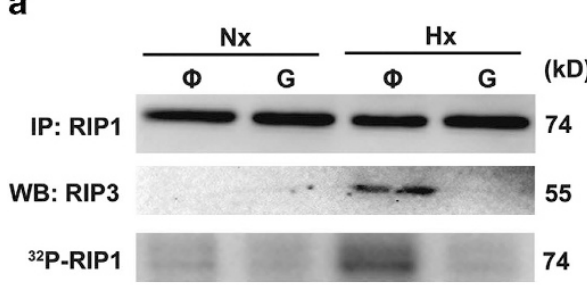

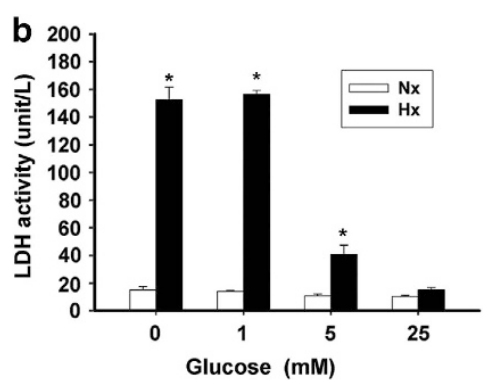

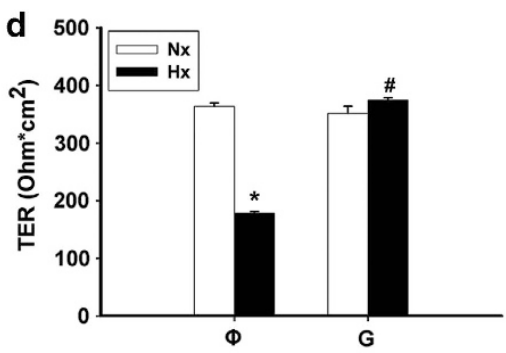

f

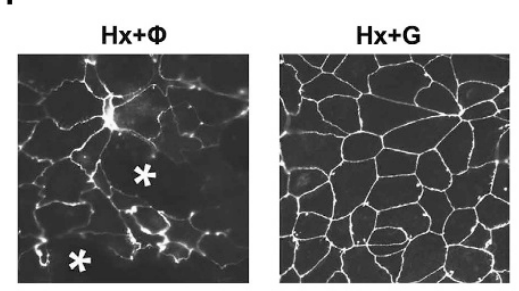

Figure 3 Supplementation of glucose prevented hypoxia $(\mathrm{Hx})$-induced necropoptosis in colonic cancer cells. Cells exposed to normoxia $(\mathrm{Nx})$ and $\mathrm{Hx}$ were given glucose (0 or $25 \mathrm{mM}$ ) to evaluate death resistance. (a) Immunoprecipitation blots showing the formation of RIP1-RIP3 complex and phosphorylation of RIP1 in hypoxic cells without supplementation (labeled as ' $\Phi^{\prime}$ ). No sign of RIP signaling was seen in hypoxic cells added $25 \mathrm{mM}$ of glucose (labeled as ' $G$ '), and normoxic counterparts with or without glucose. The experiments were repeated twice and similar results were obtained ( $n=3 /$ group). (b) The Hx-induced LDH leakage was decreased by glucose in a dosedependent manner. (c) The changes in mitochondrial transmembrane potential caused by hypoxic challenge were inhibited by glucose addition. (d) The TER drop caused by $\mathrm{Hx}$ was reversed in cells treated with glucose compared with those without glucose. (e) Addition of glucose prevented the increased dextran permeability caused by $\mathrm{Hx}$. (f) Representative images of tight junction ZO-1 staining in cells exposed to $\mathrm{Hx}$ for $16 \mathrm{~h}$ with or without glucose. Hx-induced tight junctional disruption and cell detachment (asterisks) was prevented by glucose. (b-e) ${ }^{*} P<0.05$ versus respective Nx groups; ${ }^{\#} P<0.05$ versus ' $\mathrm{Hx}+\Phi^{\prime}$ ' $n=6 /$ group)

reduced the $\mathrm{LDH}$ leakage, RIP1/3 complex formation and morphological damage in hypoxic cells (Figure 6a-c). However, the ATP levels in cells given pyruvate were comparable to those without supplementation (Figure 6d). Presence of pyruvate neither altered cellular ATP contents nor suppressed dextran flux in hypoxic cells (Figure 6e), indicating that death resistance by pyruvate was uncoupled with ATP production and energy-dependent processes (e.g., tight junctional restoration). Unlike glucose, pyruvate did not suppress $\mathrm{Hx}$-induced mitochondrial transmembrane potential changes (Figure 6f). These results suggest that pyruvate confers resistance to necroptosis through an alternative, energy-independent mechanism.

Generation of mitochondria-derived oxidative free radicals has been implicated in the cell necrotic pathways triggered by cytotoxic agents, ${ }^{18,21}$ and we sought to examine its role in hypoxic necrosis. Increased mean fluorescence of MitoSox (an indicator of mitochondrial superoxide production) was observed in hypoxic cells compared with normoxic controls in glucose-free media (Figure 7a). Decreasing the mitochondrial superoxide levels with butylated hydroxyanisole (BHA, a free radical scavenger) and apocynin (an inhibitor to nicotinamide adenine dinucleotide phosphate oxidase) (Figure 7a) led to partial inhibition of LDH leakage in hypoxic cells (Figure 7b). Moreover, pretreatment with BHA also diminished the RIP1/3 complex formation (Figure 7c). These results indicate that ROS production, which is upstream of RIP signaling, is involved in $\mathrm{Hx}$-induced necroptotic pathways.

The modulatory effect of glucose and pyruvate on free radical levels was next addressed. Addition of glucose decreased $\mathrm{Hx}$-induced mitochondrial ROS levels (Figure 7d), but did not alter the redox activities of catalase, superoxide dismutase, glutathione reductase or glutathione-S-transferase (Supplementary Figure S5), suggesting a non-enzymatic scavenging mechanism. The glucose-mediated reduction of mitochondrial ROS may be inhibited by pretreatment with IA but not with UK (Figure 7d). Lastly, replacing glucose with cell-permeable pyruvate derivative also significantly suppressed the mitochondrial ROS levels in hypoxic cells (Figure 7d). Similar results of pyruvate-mediated resistance were seen in HT29 cells under hypoxic stress (Supplementary Figure S4-B, E). 
a

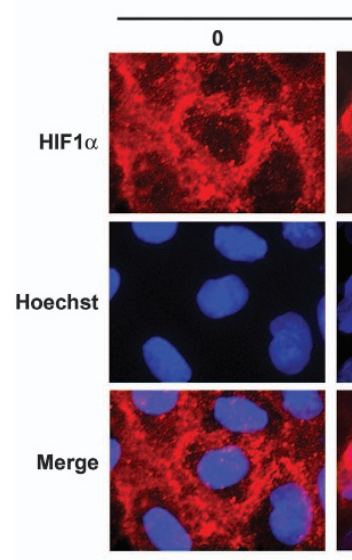

C
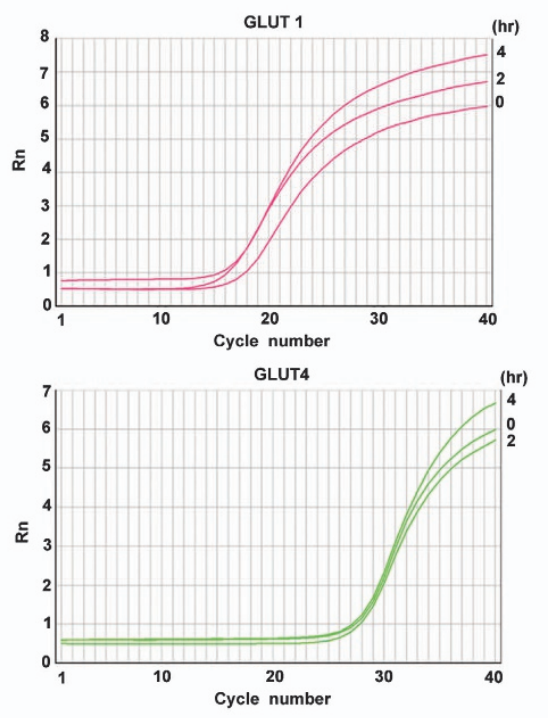

b
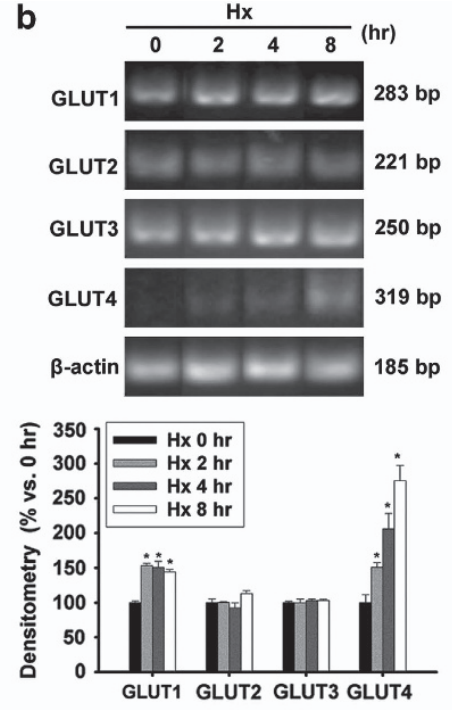

d
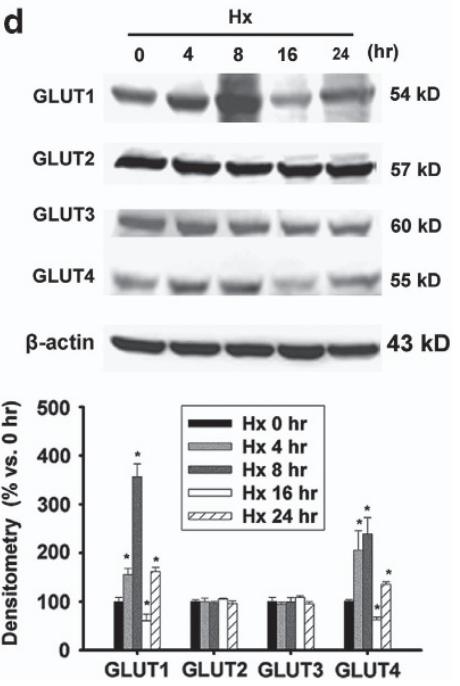

Figure 4 Hypoxic challenge induced HIF1 $\alpha$ activation and hypoxia (Hx)-targeted gene (GLUT-1 and GLUT-4) expression in the presence of glucose. (a) Representative immunofluorescence staining of HIF1 $\alpha$ in hypoxic cells given glucose for 0,2 and $4 \mathrm{~h}$. Superimposed images of HIF1 $\alpha$ staining (red) merged with cell nucleus (blue) showed cytoplasmic distribution of HIF1 $\alpha$ under normoxic conditions and nuclear translocation of HIF- $1 \alpha$ after hypoxic challenge for 2 and $4 \mathrm{~h}$ ( $n=6 / \mathrm{group}$ ). (b) The mRNA levels of GLUT-1, GLUT-2, GLUT-3 and GLUT-4 following hypoxic challenge as determined by semiquantitative PCR analysis. (c) Representative quantification of mRNA expression of GLUT-1 and GLUT-4 in hypoxic cells by real-time PCR. (d) The protein levels of GLUT-1, GLUT-2, GLUT-3 and GLUT-4 after hypoxic challenge as determined by western blots. (b and d) ${ }^{*} P<0.05$ versus ' 0 h'. ( $n=4 /$ group)

\section{Discussion}

Malignant cells develop adaptive mechanisms to evade necrotic death caused by depletion of oxygen and nutrients. Our study demonstrates a novel mechanism through which glycolytic pyruvate confers resistance to RIP-dependent necroptosis in hypoxic colorectal carcinoma via mitochondrial superoxide scavenging. To the best of our knowledge, this study is the first to provide evidence of anti-necroptotic pathways against hypoxic stress in colorectal cancer cells.

Despite long-standing observation of cell necrosis in the hypoxic core of colorectal tumors, there is an apparent lack of knowledge on its molecular mechanisms. In our study, we demonstrated that oxygen and glucose deprivation induced RIP1/3 signaling and morphological necrotic features, that is, rupture of plasma membrane, $8-24 \mathrm{~h}$ after the onset of challenge in colorectal carcinoma cells. Recent studies from other laboratories have also showed necroptosis in intestinal epithelial cells in models of chronic intestinal inflammation in gene-deficient mice. ${ }^{29,30}$ Although there is no data on the timing of necrotic death caused by hypoxic stress in normal human epithelial cells, rapid villous necrosis in jejunum and colon was found in rats after $60 \mathrm{~min}$ of hemorrhagic shock or $40 \mathrm{~min}$ of mesenteric ischemia, ${ }^{31,32}$ showing that normal cells are more sensitive to oxygen and nutrient deprivation compared with cancer cells. It is noteworthy that normoxic controls in glucosefree media displayed no sign of necroptosis, indicating that glucose deprivation alone did not trigger necrotic death.

Mitochondrial dysfunctions and free radical generation have also been implicated in the necrotic process caused by cytotoxic agents. ${ }^{20,21,33}$ The transient mitochondrial 

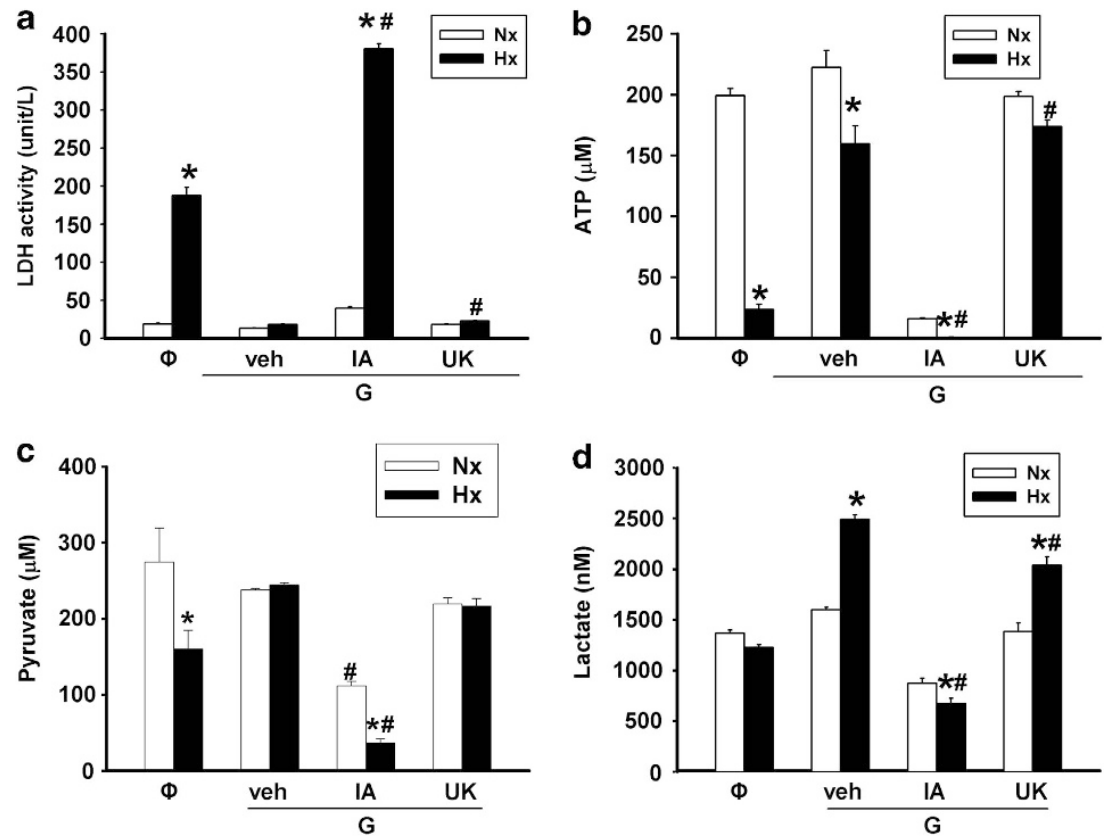

Figure 5 Anti-necrotic resistance of human colonic carcinoma cells was associated with anaerobic glycolytic metabolism. Cells were pretreated with vehicle (veh), iodoacetate (IA, $1 \mathrm{mM}$; a glycolytic inhibitor to GPD) or UK5099 (UK, $10 \mu \mathrm{M}$; a MPC inhibitor) prior to hypoxic challenge in the presence of glucose. The LDH activity in cell media (a) and the intracellular levels of ATP (b), pyruvate (c) and lactate (d) were measured. (a-d) ${ }^{*} P<0.05$ versus respective normoxia (Nx) groups; ${ }^{\#} P<0.05$ versus 'veh' ( $n=8 /$ group $)$

a

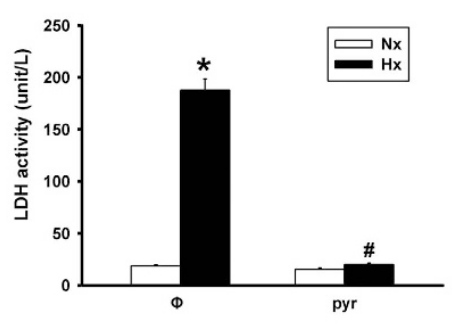

b

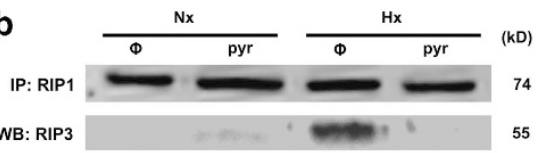

C

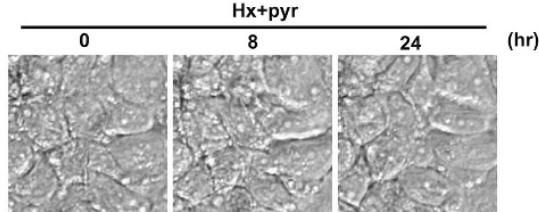

d

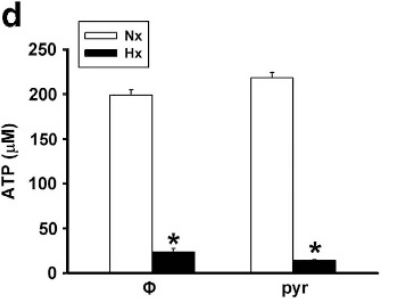

e

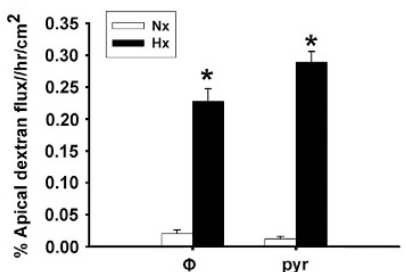

$\mathbf{f}$

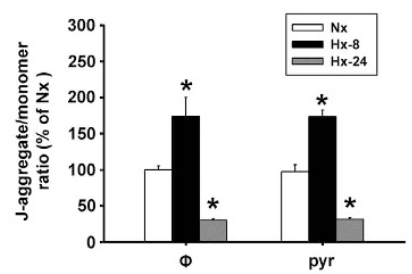

Figure 6 Pyruvate inhibited hypoxia $(\mathrm{Hx})$-induced necrotic death in an energy-independent mechanism. Colonic cancer cells were normoxia ( $\mathrm{Nx}$ ) and $\mathrm{Hx}$ exposed in the absence $(\Phi)$ or presence of ethyl pyruvate (pyr; $25 \mathrm{mM}$ ). Addition of pyruvate derivative prevented the LDH leakage (a), RIP1/3 complex formation (b) and morphological damage (c) caused by Hx. However, the cellular ATP levels (d), barrier function (e) and mitochondrial transmembrane potential (f) were not restored by pyruvate. (a, $d-f)$ ${ }^{*} P<0.05$ versus respective Nx groups; ${ }^{\#} P<0.05$ versus ' $\mathrm{Hx}+\Phi$ '. (a and $\mathbf{d}, n=8 /$ group; $\mathbf{b}, \mathbf{c}$, e and $\mathbf{f}, n=4 /$ group)

hyperpolarization observed in our study may reflect a temporal reversal of electron transport chain ATP synthase activity because of a decline in intracellular oxygen, leading to adverse proton pumping against the electrochemical gradient to intermembranous spaces. Moreover, the final mitochondrial potential collapse correlated well with organelle swelling at later time points (16-24 h) of $\mathrm{Hx}$. Interestingly, we identified high levels of mitochondrial superoxide production prior to plasma membrane disintegration in hypoxic colonic carcinoma cells. This seemingly paradoxical situation of ROS emission in $\mathrm{Hx}$ has also been previously documented in cardiomyocytes after infarction. ${ }^{34,35}$ The generation of mitochondrial ROS has been suggested to be caused by electron leak to oxygen in the respiratory chain complexes, whereby 
a

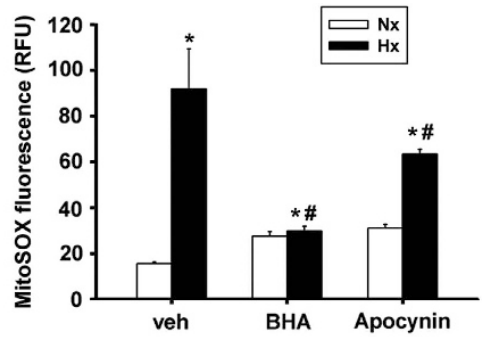

C

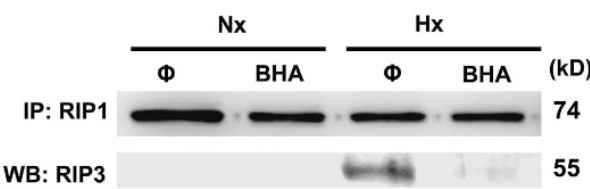

${ }^{120}$
0
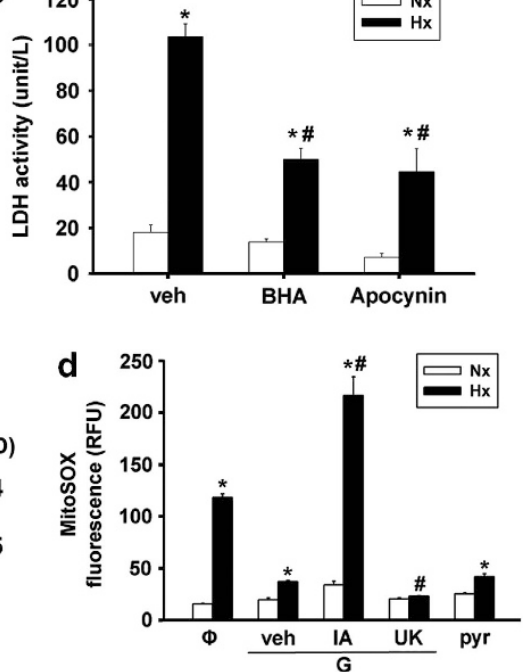

Figure 7 Pyruvate-mediated mitochondrial superoxide scavenging has a critical role in resistance to hypoxia (Hx)-induced necroptosis. (a) Increased MitoSOX fluorescence units were seen in hypoxic cells at the 8-h time point, suggesting mitochondrial superoxide production upon hypoxic stress. The generation of mitochondrial ROS may be partially prevented by antioxidants ( $200 \mu \mathrm{M}$ BHA or $1 \mathrm{mM}$ apocynin), whereas vehicle control (veh) had no effect. ${ }^{*} P<0.05$ versus respective normoxia (Nx) groups; ${ }^{\#} P<0.05$ versus 'veh' ( $n=8$ /group). (b) The Hx-induced LDH leakage was abolished by pretreatment with antioxidants, suggesting that cell necrosis was dependent on mitochondrial ROS production. ${ }^{*} P<0.05$ versus respective Nx groups; ${ }^{*} P<0.05$ versus 'veh' ( $n=8 /$ group). (c) Immunoprecipitation blots showing the formation of RIP1/3 complex in hypoxic cells, which was inhibited by BHA. The experiments were repeated twice and similar results were obtained. ( $n=3 /$ group). (d) Supplementation of glucose decreased mitochondrial ROS levels in hypoxic cells, which was reversed by pretreatment with iodoacetate (IA, $1 \mathrm{mM}$ ), but not UK5099 (UK, $10 \mu \mathrm{M})$ or vehicle (veh). Replacing glucose with a pyruvate derivative (pyr) also reduced mitochondrial ROS in hypoxic cells. * $P<0.05$ versus respective Nx groups; " $P<0.05$ versus 'veh'. ( $n=8 /$ group)

low levels of oxygen remain inside cells at the early stage of hypoxic challenge. ${ }^{36}$ By using antioxidants, we demonstrated that mitochondria-derived superoxide has a critical role in $\mathrm{Hx}$-induced necrotic mechanisms and is upstream of RIP signals.

We further showed that GLUT-dependent glucose uptake and glycolytic metabolism inhibits $\mathrm{Hx}$-induced RIP signaling and necrotic features in colorectal cancer cells. Several studies have implicated that glycolytically generated ATP may restore energy supply in cancer cells and act as a key factor for glucose-mediated death resistance against $\mathrm{Hx}$ and genotoxic agents. ${ }^{27,28}$ Recent data in activated macrophages and $B$ lymphocytes have demonstrated that glycolytic ATP promotes cell survival via maintenance of transmembrane potential of defective mitochondria that are unable to generate ATP ${ }^{37,38}$ Here, we focused on the role of glycolytic pyruvate, and examined if cell-permeable derivative may lead to anti-necrotic effects. We demonstrated that $\mathrm{Hx}$-induced necroptosis (i.e., LDH leakage, RIP activation and morphological damage) was reverted by pyruvate; however, the resistance was uncoupled with restoration of cellular energy and mitochondrial potential. Another line of evidence showed that glucose addition reduced the mitochondrial ROS levels but did not alter the redox enzyme activity. The aforementioned data indicate that a non-enzymatic free radical scavenging mechanism, such as those reported with pyruvate, may contribute to death resistance. Indeed, our results showed that supplementation of pyruvate significantly reduced the mitochondrial superoxide levels in hypoxic cells in an ATP-independent manner. It is noteworthy that glucosemediated recovery of mitochondrial transmembrane potential in hypoxic cells is not dependent on pyruvate but may rely on ATP. Taken together, glycolytic metabolism may promote hypoxic cell survival by a twofold mechanism, including scavenging of mitochondrial superoxide by pyruvate and maintenance of mitochondrial potential by ATP.

We confirmed that presence of glucose during hypoxic challenge did not ablate oxygen deprivation stress as evidenced by the nuclear translocation of HIF1 $\alpha$. The HIF1targeted upregulation of GLUTs led to enhanced glucose uptake and glycolytic metabolism, serving as a positive cycle to promote cell survival. Normal human small intestinal epithelial cells express SGLT1 on apical membrane and GLUT-2 on basolateral membrane for luminal-to-serosal flux of dietary glucose absorption. ${ }^{39,40}$ In contrast to normal colonocytes, human colorectal carcinoma specimens abnormally display SGLT1 and GLUT isoforms 1-4 on the apical membrane or cytoplasm of tumor cells. ${ }^{6-8}$ Previous studies have indicated that transcriptional regulation of GLUT-1 is mediated by HIF1 binding to a nucleotide sequence corresponding to a Hx-responsive element in promoter regions of GLUT-1 gene, following oxygen deprivation. ${ }^{41,42}$

Other than GLUTs (GLUT-1 and GLUT-3), a large number of genes encoding for glycolytic enzymes, angiogenic growth factors, cell survival and proliferative signals, and prolyl hydroxylases (PHD) are also upregulated by HIF1.4,5,43 In our study, a transient drop of GLUTs expression was observed after $16 \mathrm{~h}$ but recovered after $24 \mathrm{~h}$ of $\mathrm{Hx}$. The temporary reduction of GLUTs expression may be because of the regulatory loop of $\mathrm{HIF} 1 \alpha / \mathrm{PHD}$. Under normoxic conditions, PHD-mediated hydroxylation of proline residues on HIF1 $\alpha$ permits its ubiquitination followed by proteosomal 
degradation. Hx sensing downregulates PHD activity and thus, stabilizes HIF $1 \alpha$ levels, leading to its nuclear translocation and downstream transcription of target genes. ${ }^{44,45}$ Paradoxically, PHDs are themselves target genes of HIF1 transcription, indicating a negative feedback mechanism. ${ }^{46,47}$ In addition, HIF $1 \alpha$ degrades within $8-12 \mathrm{~h}$ without de novo synthesis. ${ }^{48}$ Therefore, we speculate that the fluctuation of GLUTs expression after the onset of $\mathrm{Hx}$ may reflect the HIF $1 \alpha$ / PHD loop. Experiments to address the temporal relationship, cellular distribution and pathophysiological significance of various isoforms of GLUTs by HIF1 in colonic carcinoma are currently under progress.

Angiogenic pathways and mediators have been extensively studied as potential anti-cancer drugs for several decades. In some cases, patients fail to respond to antiangiogenic agents or simply develop drug resistance. Tumors may display invasive metastatic transition in response to the increasing hypoxic microenvironment by cancer treatment. ${ }^{49,50}$ Here, our data show a critical role of glycolytic pyruvate in death resistance and underscore site-specific GLUTs and metabolic pathways as potential candidates for the development of novel cancer-killing strategies. The resistance to antiangiogesis or hypoxic stress may be overcome by combinational strategies with glucose- or pyruvate-targeted therapy.

In conclusion, glycolytic metabolism inhibits $\mathrm{Hx}$-induced RIP-dependent necroptosis in colonic cancer cells by suppression of mitochondrial ROS. The understanding of resistance to hypoxic necrosis by glucose and pyruvate may benefit the development of novel therapeutic targets for treating colorectal carcinoma.

\section{Materials and Methods}

Cell culture models. Human colonic carcinoma Caco-2 and HT29 cells were grown in Dulbecco's modified Eagle's medium (Invitrogen, Grand Island, NY, USA) containing $5 \mathrm{mM}$ glucose and without pyruvate. ${ }^{39,51}$ The media was supplemented with $10 \%$ fetal bovine serum, $15 \mathrm{mM}$ HEPES, $100 \mathrm{U} / \mathrm{ml}$ penicillin and $0.1 \mathrm{mg} / \mathrm{ml}$ streptomycin (Sigma, St. Louis, MO, USA). Cells were seeded in 96-well $\left(10^{5}\right.$ cells/well) or 24-well $\left(10^{6}\right.$ cells/well) tissue culture plates (Costar, Corning, NY, USA). Cells were grown to confluency for 1 week at $37^{\circ} \mathrm{C}$ with $5 \% \mathrm{CO}_{2}$ and $96 \%$ humidity. In all studies, cells were used between passages 21 and 27 .

Hypoxic challenge and glucose deprivation. Cells were deprived of oxygen and glucose as previously described. ${ }^{51-53}$ Hypoxic $(\mathrm{Hx})$ challenge was conducted using a modular incubator chamber (Billups-Rothenberg, Del Mar, CA, USA) by infusion of $5 \% \mathrm{CO}_{2}$ and $95 \% \mathrm{~N}_{2}$ at $10 \mathrm{l} / \mathrm{min}$ for $5 \mathrm{~min}$; normoxic ( $\mathrm{Nx}$ ) controls were kept at $5 \% \mathrm{CO}_{2}$ and $95 \%$ air. ${ }^{51-53}$ In some groups, cells were pretreated with Nec-1 (a specific RIP1 inhibitor), BHA (200 $\mu \mathrm{M}$; a free radical scavenger), apocynin ( $1 \mathrm{mM}$; an inhibitor to nicotinamide adenine dinucleotide phosphate oxidase) or vehicle controls prior to hypoxic challenge to examine cell death pathways.

In additional experiments, cells were incubated in glucose-free and pyruvate-free Dulbecco's modified Eagle's media (Invitrogen) supplemented as above plus 0-25 mM glucose. To verify the role of glycolysis in death resistance, cells were pretreated with inhibitors to the cascade of glucose metabolic pathways such as IA (1 mM; a glycolytic inhibitor to GPD) and UK (10 $\mu \mathrm{M}$; a MPC inhibitor), or with vehicle controls prior to hypoxic challenge in the presence of glucose. In another set of experiments, equimolar concentrations of substances were apically instilled in place of glucose to verify cellular metabolic status, such as 3-0-methylglucopyranoside (a non-metabolizable sugar analog taken up by GLUTs), mannitol (a non-absorbable and non-metabolizable sugar used as an osmolarity control), or glutamate (an amino acid used as an oxidative fuel control) before hypoxic challenge. The anti-necrosis effect of a cell-permeable pyruvate derivative, ethyl pyruvate $(25 \mathrm{mM})$, was also examined in hypoxic cells. All reagents were purchased from Sigma.
LDH leakage assay. The leakage of intracellular enzyme LDH into the surrounding environment indicates rupture of plasma membrane, which is a hallmark of cell necrosis. The cell culture supernatant was collected after hypoxic challenge for the measurement of LDH activity. Briefly, a reaction mixture of $0.2 \mathrm{mM}$ NADH and $0.36 \mathrm{mM}$ sodium pyruvate was dissolved in Krebs-Henseleit $(\mathrm{K}-\mathrm{H})$ buffer containing $2 \%$ bovine serum albumin. The $\mathrm{K}-\mathrm{H}$ buffer is composed of $118 \mathrm{mM} \mathrm{NaCl}, 4.8 \mathrm{mM} \mathrm{KCl}, 1.2 \mathrm{mM} \mathrm{MgSO}_{4}, 1.25 \mathrm{mM} \mathrm{CaCl}_{2}, 1.2 \mathrm{mM} \mathrm{KH}_{2} \mathrm{PO}_{4}$ and $24 \mathrm{mM} \mathrm{NaHCO}_{3}(\mathrm{pH}$ 7.4). Ten microliters of cell supernatant and $190 \mu \mathrm{l}$ of reaction mixture were mixed well in 96-well plates prior to spectrophotometric kinetic readings. Owing to the differences in the absorption spectra of $\mathrm{NADH}$ and $\mathrm{NAD}^{+}$, changes in the NADH concentration can be detected at $340 \mathrm{~nm}$. The decrease in absorbance measured every minute over a 10-min period represents the activity of $\mathrm{LDH}$. One unit of LDH activity is defined as the quantity for oxidation of $1 \mu \mathrm{mol}$ NADH per minute; the LDH activity of cell supernatant was expressed in Units per liter (Unit/l).

Analysis of mitochondrial functions by time-lapse microscopy. Mitochondrial transmembrane potential changes and ROS production were measured by using cell-permeant cationic fluorescent dyes, including $5,5^{\prime}, 6,6^{\prime}$ tetrachloro-1.1',3,3'-tetraethylbenzimidazolylcarbocyanine iodide (JC-1) reagents and MitoSOX (Invitrogen). The JC-1 reagent emits red fluorescence in its aggregated form when it accumulates in the negatively charged mitochondrial matrix of viable cells. The monomeric form of JC-1 emits green fluorescence when the dye is dispersed in the cytoplasm because of the loss of mitochondrial transmembrane potential. MitoSOX Red, which selectively targets functional mitochondria, exhibits red fluorescence after oxidization by superoxide. Cells grown on 96-well culture plates or 8-well chamber slides $\left(2 \times 10^{5} \mathrm{cells} / \mathrm{well}\right.$, Costar) were incubated with $\mathrm{JC}-1(10 \mu \mathrm{g} / \mathrm{ml})$ or MitoSOX $(5 \mu \mathrm{M})$ for $20 \mathrm{~min}$, and washed twice prior to hypoxic challenge, and then subjected to fluoremetric readings. Alternatively, cells were analyzed by time-lapse microscopy using Application Solution Multi-Dimensional Workstation (Leica Microsystems, Mannheim, Germany). Cells were loaded with JC-1 $(10 \mu \mathrm{g} / \mathrm{ml})$ for $30 \mathrm{~min}$ before infusion of $5 \% \mathrm{CO}_{2}$ and $95 \% \mathrm{~N}_{2}$ into the temperature-controlled moisture chamber of the Application Solution Multi-Dimensional Workstation for live cell imaging.

Immunoprecipitation of RIP1-RIP3 complex and in vitro kinase assay. Cells lysates were immunoprecipitated with anti-human RIP1 (BD Biosciences, Franklin Lakes, NJ, USA) overnight and then incubated with protein $\mathrm{G}$ agarose beads for $1 \mathrm{~h}$ at $4{ }^{\circ} \mathrm{C}$ followed by centrifugation. The pellet was dissolved in electrophoresis sample buffer for heat denaturation. The immune complexes were subjected to reducing SDS-PAGE, and the membranes were incubated with anti-RIP1 (1:1000, BD Biosciences) or polyclonal rabbit anti-RIP3 (1:1000, Abcam, Cambridge, UK) for immunoblotting. For in vitro kinase assays, the bead pellets were incubated in kinase reaction buffer supplemented with $10 \mu \mathrm{M}$ cold ATP and $1 \mu \mathrm{Ci} \gamma^{32} \mathrm{P}$-ATP for $30 \mathrm{~min}$ at $30^{\circ} \mathrm{C}$. The samples were resolved by SDS-PAGE and exposed to film for autoradiography as previously described. ${ }^{19}$

RNAi-mediated knockdown of RIP1. RIP1 siRNA and negative control were purchased from Dharmacon, Lafayette, CA, USA. Cells were transfected with $100 \mathrm{nM}$ siRNA oligonucleotides using DharmaFECT siRNA transfection reagents as per manufacturer's protocol. Knockdown efficiency of transfected cells was confirmed by western blotting $96 \mathrm{~h}$ post transfection.

Measurement of TER and paracellular permeability. Cells grown to confluency underwent $\mathrm{Nx}$ or $\mathrm{Hx}$ for the indicated times. The monolayer TER was measured using an electrovoltohmeter (World Precision Instruments, Sarasota, FL, USA). Paracellular permeability was assessed by apical-to-basal transport of a dextran probe (MW3000) conjugated to fluorescein (Invitrogen) as described previously. ${ }^{39,54}$

Immunofluorescent staining of tight junction structures. Cells were exposed to $\mathrm{Nx}$ or $\mathrm{Hx}$ for $16 \mathrm{~h}$, fixed with $4 \%$ paraformaldehyde for $1 \mathrm{~h}$ on ice and quenched with $50 \mathrm{mM} \mathrm{NH}_{4} \mathrm{Cl}$ in PBS for $10 \mathrm{~min}$ at room temperature. After blocking with $0.1 \%$ bovine serum albumin in PBS for $1 \mathrm{~h}$, monolayers were incubated with a polyclonal rabbit anti-human ZO-1 antibody (1:100, Invitrogen) in a permeabilizing buffer $(0.05 \%$ saponin and $0.1 \%$ bovine serum albumin in PBS) for $1 \mathrm{~h}$. Cells were then incubated with secondary antibodies of goat anti-rabbit lgG conjugated to Alexa 488 (1:1000, Invitrogen) for $1 \mathrm{~h}$ in the dark and then stained 
with a Hoechst dye to visualize cell nuclei. The slides were mounted with aqueous mounting media and viewed under a Zeiss fluorescence microscope.

Measurement of cell apoptosis. DNA fragmentation, which is a final stage of apoptosis, was measured using a cell detection ELISA kit (Roche Applied Science, Indianapolis, IN, USA) for oligonucleosome amount as previously described. ${ }^{39}$ The caspse-3 activity assay (Anaspec, Fremont, CA, USA) was based on spectrophotometric detection of chromophore rhodamine 110 after cleavage from the labeled substrate DEVD-rhodamine 110 according to the manufacturer's instructions. ${ }^{55}$

RNA extraction and polymerase chain reaction for GLUT transcripts. Total RNA was isolated using Trizol reagent (Invitrogen) according to the manufacturer's instructions. For semiquantitative polymerase chain reaction (PCR) analysis, the RNA $(2 \mu \mathrm{g})$ was reverse transcribed with oligo(dT) using RevertAid First Strant cDNA Synthesis kit (Thermo Scientific, West Palm Beach, FL, USA) in $20 \mu \mathrm{l}$ reaction volume. The reverse transcribed product corresponding to $0.1 \mu \mathrm{g}$ of initial RNA was subjected to PCR amplification in a thermal cycler. The specific primer pairs of human GLUTs $1-4$ and $\beta$-actin and the thermal cycling procedures were described previously. ${ }^{56}$ The amplification conditions were as followed: denaturation at $95^{\circ} \mathrm{C}$ for $30 \mathrm{~s}$, annealing at $60^{\circ} \mathrm{C}$ for $30 \mathrm{~s}$ and extension at $72{ }^{\circ} \mathrm{C}$ for $50 \mathrm{~s}$ in a total of $30 \mathrm{cycles}$. The PCR products were separated onto $1 \%$ agarose gel containing ethidium bromide and visualized by ultraviolet transillumination.

Quantitative real-time PCR analysis was carried out using an Applied Biosystems 7500 real-time PCR system (Applied Biosystems, Grand Island, NY, USA). The PCR reaction mixture consisted of $50 \mathrm{ng}$ of reverse transcribed product, $10 \mu \mathrm{l}$ of Power SYBR Green PCR Master Mix (Applied Biosystems) and $500 \mathrm{nM}$ specific primer pairs in a final reaction volume of $20 \mu \mathrm{l}$. The specific primer pairs of human GLUT-1, GLUT-4 and $\beta$-actin were described previously. ${ }^{57,58}$ The PCR conditions were $95^{\circ} \mathrm{C}$ for $10 \mathrm{~min}$, followed by 40 cycles of denaturation at $95^{\circ} \mathrm{C}$ for $15 \mathrm{~s}$, and annealing and extension at $56^{\circ} \mathrm{C}$ for $1 \mathrm{~min}$. Amplification plots were obtained by using a Sequence Detection Software (Applied Biosystems).

Western blotting for GLUT proteins. Extracted protein samples were subjected to SDS-PAGE (4-13\% polyacrylamide) as described. ${ }^{54,55}$ Briefly, the resolved proteins were electrotransferred onto PVDF membranes and blocked with $5 \%(\mathrm{w} / \mathrm{v})$ nonfat dry milk in Tris-buffered saline (TBS) for $1 \mathrm{~h}$, washed three times with TBS-T $(0.1 \%(\mathrm{v} / \mathrm{v})$ Tween-20 in TBS) and then incubated with primary antibodies at $4{ }^{\circ} \mathrm{C}$ overnight. After washing with TBS-T, the membrane was incubated with a secondary antibody for $1 \mathrm{~h}$ and then washed again. The membranes were incubated with chemiluminescent solution (ECL, Millipore, Billerica, MA, USA) and signal was detected on an UVP AutoChemi system (UVP, Upland, CA, USA). Band density was determined using the software Gel-pro Analyzer 4.0 (Media Cybernetics, Rockville, MD, USA).

The primary antibodies used for blotting included anti-GLUT-1 (1:2000, Millipore), anti-GLUT-2 (1:1000, Millipore), anti-GLUT-3 (1:1000, Millipore), anti-GLUT-4 (1:1000, Millipore) and anti- $\beta$-actin (1:10000, Sigma). The secondary antibody used were horseradish peroxidase-conjugated goat anti-rabbit IgG (1:1000, Cell Signaling, Danvers, MA, USA).

Measurement of intracellular redox enzyme activities. The activities of catalase, superoxide dismutase, glutathione reductase or glutathione-S-transferase were measured in cell lysates using commercial assay kits (Cayman Chemical, Ann Arbor, MI, USA) following the manufacturer's instructions.

Measurement of intracellular pyruvate, ATP and lactate contents. Cell lysates were used for the assessment of intracellular pyruvate (Biovision, Milpitas, CA, USA), ATP (Invitrogen) and lactate (Biovision) levels using commercial assay kits. To measure the pyruvate concentration in the cell, pyruvate is served as a substrate oxidized by pyruvate oxidase via enzyme reaction to generate color and analysis at OD $570 \mathrm{~nm}$ by plate reader. The ATP assay is based on requirement of ATP by luciferase for light production, and the luminescence is measured using a luminometer. To quantify lactate content, a chromogenic assay utilizing cellular lactate as a substrate oxidized by lactate dehydrogenase was measured at $450 \mathrm{~nm}$ by a plate reader.

Statistical analysis. All values were expressed as mean \pm S.E.M. and the means were compared by one-way analysis of variance followed by a Student-Newman-Keul test. Significance was established at $P<0.05$.

\section{Conflict of Interest}

The authors declare no conflict of interest.

Acknowledgements. We thank the staff of the imaging core at the First Core Labs, National Taiwan University College of Medicine for technical assistance. This study was supported by grants from the National Science Council (NSC 99-2320-B002-024-MY3; NSC 101-2325-B-002-031) and National Taiwan University (10R71807).

\section{Author contributions}

LC-HY and C-YH designed the research; C-YH, W-TK and Y-CH conducted the research; C-YH, T-CL and LC-HY analyzed the data; LC-HY, C-YH and T-CL wrote the paper (and made a major contribution).

1. Cuezva JM, Krajewska M, de Heredia ML, Krajewski S, Santamaria G, Kim H et al. The bioenergetic signature of cancer: a marker of tumor progression. Cancer Res 2002; 62 : 6674-6681.

2. Sanchez-Arago M, Cuezva JM. The bioenergetic signature of isogenic colon cancer cells predicts the cell death response to treatment with 3-bromopyruvate, iodoacetate or 5-fluorouracil. J Transl Med 2011; 9: 19

3. Hamanaka RB, Chandel NS. Targeting glucose metabolism for cancer therapy. J Exp Med 2012; 209: 211-215.

4. Chiacchiera F, Matrone A, Ferrari E, Ingravallo G, Lo Sasso G, Murzilli S et al. p38alpha blockade inhibits colorectal cancer growth in vivo by inducing a switch from HIF1alpha- to FoxO-dependent transcription. Cell Death Differ 2009; 16: 1203-1214.

5. Marin-Hernandez A, Gallardo-Perez JC, Ralph SJ, Rodriguez-Enriquez S, Moreno-Sanchez R. HIF-1alpha modulates energy metabolism in cancer cells by inducing over-expression of specific glycolytic isoforms. Mini Rev Med Chem 2009; 9: 1084-1101.

6. de Wit M, Jimenez CR, Carvalho B, Belien JA, Delis-van Diemen PM, Mongera S et al. Cell surface proteomics identifies glucose transporter type 1 and prion protein as candidate biomarkers for colorectal adenoma-to-carcinoma progression. Gut 2012; 61: 855-864.

7. Godoy A, Ulloa V, Rodriguez F, Reinicke K, Yanez AJ, Garcia Mde L et al. Differential subcellular distribution of glucose transporters GLUT1-6 and GLUT9 in human cancer: ultrastructural localization of GLUT1 and GLUT5 in breast tumor tissues. J Cell Physiol 2006; 207: 614-627.

8. Guo GF, Cai YC, Zhang B, Xu RH, Qiu HJ, Xia LP et al. Overexpression of SGLT1 and EGFR in colorectal cancer showing a correlation with the prognosis. Med Oncol 2011; 28(Suppl 1): S197-S203.

9. Wincewicz A, Baltaziak M, Kanczuga-Koda L, Koda M, Sulkowska U, Sulkowski S. GLUT1 and $\mathrm{Bcl}-\mathrm{xL}$ in relation to erythropoietin in human colorectal adenocarcinomas. Hepatogastroenterology 2010; 57: 741-745.

10. Hanabata Y, Nakajima Y, Morita K, Kayamori K, Omura K. Coexpression of SGLT1 and EGFR is associated with tumor differentiation in oral squamous cell carcinoma. Odontology 2012; 100: 156-163.

11. Casneuf VF, Fonteyne $P$, Van Damme N, Demetter $P$, Pauwels $P$, de Hemptinne $B$ et al. Expression of SGLT1, Bcl-2 and p53 in primary pancreatic cancer related to survival. Cancer Invest 2008; 26: 852-859.

12. Leiprecht N, Munoz C, Alesutan I, Siraskar G, Sopjani M, Foller M et al. Regulation of $\mathrm{Na}(+)$-coupled glucose carrier SGLT1 by human papillomavirus $18 \mathrm{E} 6$ protein. Biochem Biophys Res Commun 2011; 404: 695-700.

13. Greijer AE, Delis-van Diemen PM, Fijneman RJ, Giles RH, Voest EE, van Hinsbergh VW et al. Presence of HIF-1 and related genes in normal mucosa, adenomas and carcinomas of the colorectum. Virchows Arch 2008; 452: 535-544.

14. Simiantonaki N, Taxeidis M, Jayasinghe C, Kurzik-Dumke U, Kirkpatrick CJ. Hypoxiainducible factor 1 alpha expression increases during colorectal carcinogenesis and tumor progression. BMC Cancer 2008; 8: 320.

15. Jilling T, Simon D, Lu J, Meng FJ, Li D, Schy R et al. The roles of bacteria and TLR4 in rat and murine models of necrotizing enterocolitis. J Immunol 2006; 177: 3273-3282.

16. Lu YZ, Wu CC, Huang YC, Huang CY, Yang CY, Lee TC et al. Neutrophil priming by hypoxic preconditioning protects against epithelial barrier damage and enteric bacterial translocation in intestinal ischemia/reperfusion. Lab Invest 2012; 92: 783-796.

17. Cho YS, Challa S, Moquin D, Genga R, Ray TD, Guildford M et al. Phosphorylation-driven assembly of the RIP1-RIP3 complex regulates programmed necrosis and virus-induced inflammation. Cell 2009; 137: 1112-1123.

18. Declercq W, Vanden Berghe T, Vandenabeele P. RIP kinases at the crossroads of cell death and survival. Cell 2009; 138: 229-232.

19. He S, Wang L, Miao L, Wang T, Du F, Zhao L et al. Receptor interacting protein kinase-3 determines cellular necrotic response to TNF-alpha. Cell 2009; 137: 1100-1111.

20. Temkin V, Huang $Q$, Liu H, Osada H, Pope RM. Inhibition of ADP/ATP exchange in receptor-interacting protein-mediated necrosis. Mol Cell Biol 2006; 26: 2215-2225.

21. Zhang DW, Shao J, Lin J, Zhang N, Lu BJ, Lin SC et al. RIP3, an energy metabolism regulator that switches TNF-induced cell death from apoptosis to necrosis. Science 2009; 325: $332-336$. 
22. Airley R, Evans A, Mobasheri A, Hewitt SM. Glucose transporter Glut-1 is detectable in peri-necrotic regions in many human tumor types but not normal tissues: Study using tissue microarrays. Ann Anat 2010; 192: 133-138.

23. Fleming SE, Zambell KL, Fitch MD. Glucose and glutamine provide similar proportions of energy to mucosal cells of rat small intestine. Am J Physiol 1997; 273(Pt 1): G968-G978.

24. Hildyard JC, Ammala C, Dukes ID, Thomson SA, Halestrap AP. Identification and characterisation of a new class of highly specific and potent inhibitors of the mitochondrial pyruvate carrier. Biochim Biophys Acta 2005; 1707: 221-230.

25. Herzig S, Raemy E, Montessuit S, Veuthey JL, Zamboni N, Westermann B et al. Identification and functional expression of the mitochondrial pyruvate carrier. Science 2012; 337: 93-96.

26. Kao KK, Fink MP. The biochemical basis for the anti-inflammatory and cytoprotective actions of ethyl pyruvate and related compounds. Biochem Pharmacol 2010; 80: 151-159.

27. Xu RH, Pelicano H, Zhou Y, Carew JS, Feng L, Bhalla KN et al. Inhibition of glycolysis in cancer cells: a novel strategy to overcome drug resistance associated with mitochondrial respiratory defect and hypoxia. Cancer Res 2005; 65: 613-621.

28. Zhou Y, Tozzi F, Chen J, Fan F, Xia L, Wang J et al. Intracellular ATP levels are a pivota determinant of chemoresistance in colon cancer cells. Cancer Res 2012; 72: 304-314.

29. Gunther C, Martini E, Wittkopf N, Amann K, Weigmann B, Neumann H et al. Caspase-8 regulates TNF-alpha-induced epithelial necroptosis and terminal ileitis. Nature 2011; 477 335-339.

30. Welz PS, Wullaert A, Vlantis K, Kondylis V, Fernandez-Majada V, Ermolaeva M et al FADD prevents RIP3-mediated epithelial cell necrosis and chronic intestinal inflammation. Nature 2011; 477: 330-334.

31. Chang JX, Chen S, Ma LP, Jiang LY, Chen JW, Chang RM et al. Functional and morphological changes of the gut barrier during the restitution process after hemorrhagic shock. World J Gastroenterol 2005; 11: 5485-5491.

32. Higa OH, Parra ER, Ab'Saber AM, Farhat C, Higa R, Capelozzi VL. Protective effects of ascorbic acid pretreatment in a rat model of intestinal ischemia-reperfusion injury: a histomorphometric study. Clinics (Sao Paulo) 2007; 62: 315-320.

33. Goossens V, Grooten J, De Vos K, Fiers W. Direct evidence for tumor necrosis factorinduced mitochondrial reactive oxygen intermediates and their involvement in cytotoxicity. Proc Natl Acad Sci USA 1995; 92: 8115-8119.

34. Becker LB, vanden Hoek TL, Shao ZH, Li CQ, Schumacker PT. Generation of superoxide in cardiomyocytes during ischemia before reperfusion. Am J Physiol 1999; 277(Pt 2): $\mathrm{H} 2240-\mathrm{H} 2246$.

35. Camara AK, Aldakkak M, Heisner JS, Rhodes SS, Riess ML, An J et al. ROS scavenging before 27 degrees $\mathrm{C}$ ischemia protects hearts and reduces mitochondrial ROS, Ca2 + overload, and changes in redox state. Am J Physiol Cell Physiol 2007; 292: C2021-C2031.

36. Turrens JF. Mitochondrial formation of reactive oxygen species. J Physiol 2003; 552(Pt 2): 335-344.

37. Dufort FJ, Bleiman BF, Gumina MR, Blair D, Wagner DJ, Roberts MF et al. Cutting edge: IL-4-mediated protection of primary B lymphocytes from apoptosis via Stat6-dependent regulation of glycolytic metabolism. J Immunol 2007; 179: 4953-4957.

38. Garedew A, Henderson SO, Moncada S. Activated macrophages utilize glycolytic ATP to maintain mitochondrial membrane potential and prevent apoptotic cell death. Cell Death Differ 2010; 17: 1540-1550

39. Yu LC, Flynn AN, Turner JR, Buret AG. SGLT-1-mediated glucose uptake protects intestinal epithelial cells against LPS-induced apoptosis and barrier defects: a novel cellular rescue mechanism? FASEB J 2005; 19: 1822-1835.

40. Yu LC, Huang CY, Kuo WT, Sayer H, Turner JR, Buret AG. SGLT-1-mediated glucose uptake protects human intestinal epithelial cells against Giardia duodenalis-induced apoptosis. Int J Parasitol 2008; 38: 923-934.

41. Hayashi M, Sakata M, Takeda T, Yamamoto T, Okamoto Y, Sawada K et al. Induction of glucose transporter 1 expression through hypoxia-inducible factor 1alpha under hypoxic conditions in trophoblast-derived cells. J Endocrinol 2004; 183: 145-154.

42. Ouiddir A, Planes C, Fernandes I, VanHesse A, Clerici C. Hypoxia upregulates activity and expression of the glucose transporter GLUT1 in alveolar epithelial cells. Am J Respir Cell Mol Biol 1999; 21: 710-718.
43. Denko NC. Hypoxia, HIF1 and glucose metabolism in the solid tumour. Nat Rev Cancer 2008; 8: 705-713.

44. Kondo S, Seo SY, Yoshizaki T, Wakisaka N, Furukawa M, Joab I et al. EBV latent membrane protein 1 up-regulates hypoxia-inducible factor 1alpha through Siah1-mediated down-regulation of prolyl hydroxylases 1 and 3 in nasopharyngeal epithelial cells. Cancer Res 2006; 66: 9870-9877.

45. Jaakkola P, Mole DR, Tian YM, Wilson MI, Gielbert J, Gaskell SJ et al. Targeting of HIF-alpha to the von Hippel-Lindau ubiquitylation complex by O2-regulated prolyl hydroxylation. Science 2001; 292: 468-472.

46. Stiehl DP, Wirthner R, Koditz J, Spielmann P, Camenisch G, Wenger RH. Increased prolyl 4-hydroxylase domain proteins compensate for decreased oxygen levels. Evidence for an autoregulatory oxygen-sensing system. J Biol Chem 2006; 281: 23482-23491.

47. Marxsen JH, Stengel P, Doege K, Heikkinen P, Jokilehto T, Wagner T et al. Hypoxiainducible factor-1 (HIF-1) promotes its degradation by induction of HIF-alpha-prolyl-4hydroxylases. Biochem J 2004; 381(Pt 3): 761-767.

48. Millonig G, Hegedusch S, Becker L, Seitz HK, Schuppan D, Mueller S. Hypoxia-inducible factor 1 alpha under rapid enzymatic hypoxia: cells sense decrements of oxygen but not hypoxia per se. Free Radic Biol Med 2009; 46: 182-191.

49. Zeng L, Biernacka KM, Holly JM, Jarrett C, Morrison AA, Morgan A et al. Hyperglycaemia confers resistance to chemotherapy on breast cancer cells: the role of fatty acid synthase. Endocr Relat Cancer 2010; 17: 539-551.

50. Rapisarda A, Melillo G. Overcoming disappointing results with antiangiogenic therapy by targeting hypoxia. Nat Rev Clin Oncol 2012; 9: 378-390.

51. Kles KA, Turner JR, Tappenden KA. Enteral nutrients alter enterocyte function within an in vitro model similar to an acute in vivo rat model during hypoxia. JPEN J Parenter Enteral Nutr 2002; 26: 71-76

52. Kalda A, Eriste E, Vassiljev V, Zharkovsky A. Medium transitory oxygen-glucose deprivation induced both apoptosis and necrosis in cerebellar granule cells. Neurosci Lett 1998; 240: 21-24.

53. Shahrzad S, Quayle L, Stone C, Plumb C, Shirasawa S, Rak JW et al. Ischemia-induced $\mathrm{K}$-ras mutations in human colorectal cancer cells: role of microenvironmental regulation of MSH2 expression. Cancer Res 2005; 65: 8134-8141.

54. Wu LL, Chiu HD, Peng WH, Lin BR, Lu KS, Lu YZ et al. Epithelial inducible nitric oxide synthase causes bacterial translocation by impairment of enterocytic tight junctions via intracellular signals of Rho-associated kinase and protein kinase C zeta. Crit Care Med 2011; 39: 2087-2098.

55. Huang CY, Hsiao JK, Lu YZ, Lee TC, Yu LC. Anti-apoptotic PI3K/Akt signaling by sodium/ glucose transporter 1 reduces epithelial barrier damage and bacterial translocation in intestinal ischemia. Lab Invest 2011; 91: 294-309.

56. Noguchi Y, Okamoto T, Marat D, Yoshikawa T, Saitoh A, Doi C et al. Expression of facilitative glucose transporter $1 \mathrm{mRNA}$ in colon cancer was not regulated by k-ras. Cancer Lett 2000; 154: 137-142.

57. Matsushita K, Uchida K, Saigusa S, Ide S, Hashimoto K, Koike Y et al. Glycolysis inhibitors as a potential therapeutic option to treat aggressive neuroblastoma expressing GLUT1. J Pediatr Surg 2012; 47: 1323-1330

58. Torres MP, Rachagani S, Purohit V, Pandey P, Joshi S, Moore ED et al. Graviola: a nove promising natural-derived drug that inhibits tumorigenicity and metastasis of pancreatic cancer cells in vitro and in vivo through altering cell metabolism. Cancer Lett 2012; 323: $29-40$.

(c) (i) $(9)$ Cell Death and Disease is an open-access journal published by Nature Publishing Group. This work is licensed under a Creative Commons Attribution-NonCommercialNoDerivs 3.0 Unported License. To view a copy of this license, visit http://creativecommons.org/licenses/by-nc-nd/3.0/

\section{Supplementary Information accompanies this paper on Cell Death and Disease website (http://www.nature.com/cddis)}

